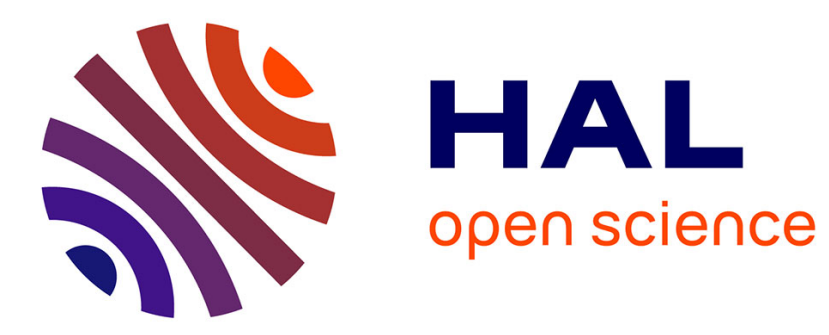

\title{
Three years of teaching resource sharing by primary school teachers trainees on a CSCW platform \\ Jean Simon
}

\section{To cite this version:}

Jean Simon. Three years of teaching resource sharing by primary school teachers trainees on a CSCW platform. 9th international conference on Computer supported collaborative learning, Jun 2009, Rhodes, Greece. pp.267-271. hal-01188707

\section{HAL Id: hal-01188707 https://hal.univ-reunion.fr/hal-01188707}

Submitted on 24 Feb 2017

HAL is a multi-disciplinary open access archive for the deposit and dissemination of scientific research documents, whether they are published or not. The documents may come from teaching and research institutions in France or abroad, or from public or private research centers.
L'archive ouverte pluridisciplinaire $\mathbf{H A L}$, est destinée au dépôt et à la diffusion de documents scientifiques de niveau recherche, publiés ou non, émanant des établissements d'enseignement et de recherche français ou étrangers, des laboratoires publics ou privés. 


\title{
Three years of teaching resource sharing by primary school teachers trainees on a CSCW platform
}

\author{
Simon Jean, ERTé CALICO, GRRAPELI, IUFM de La Réunion, Allée des Aigues Marines,97400 Saint Denis, \\ France, jean.simon@reunion.iufm.fr
}

\begin{abstract}
In this paper, we propose a unit of analysis to study traces in CSCW, the higher level shared folder ( $h l s f)$, which we define. We use it here to analyze how teaching resource pooling and sharing has been operated by the teacher trainees within the IUFM de La Réunion for three years. We verify that this sharing was effective, we see how it was structured and we study its evolution during those three years.
\end{abstract}

\section{Introduction}

The Reunion Island teacher training school (IUFM) provides courses to trainees who wish to become fully qualified teachers. In this paper, we will focus on primary teachers (PEs, i.e. professeurs des écoles). The training of primary teachers alternates according to two periods throughout the year:

- a period in the IUFM when they follow the courses;

- a period of training when they are in charge of a class and must teach pupils in a primary school.

In 2004-2005, trainers and PEs asked for a groupware (Simon, 06). We have presented in (Simon \& al, 08) the reasons of the trainers for this demand. For the PEs, the groupware should allow them to pool and share teaching material during the training period and thus reduce their workload. For them, sharing teaching material consisted in putting on line and at the disposal of the other members various types of production: lesson plans, resources which could be used by pupils during class... In September 2005, BSCW (Basic Support for Cooperative Work) (Bentley \& al, 97) was chosen as CSCW platform because it's free for an educational use and it offers a sufficiently large degree of freedom to allow easy cooperation between the various users. During three years, from September 2005 to July 2008, the different cohorts of trainees, but the same trainers, who work each year at the IUFM, have generated hundred of thousands recordings on this platform. Those recordings went from the simple consultation to the creation and the maintenance of complex shared workspaces.

We will analyze here more particularly those generated only by the PEs. We will see if there really was resource sharing when the PEs were not supervised by a trainer and how it was organized. Another element that we want to check is to see up to what point most of the PEs were involved in the process. Finally, we want to know if there is an evolution in the way they are working. But, for that, we have to use a unit of analysis smaller than the total activity of the CSCW platform which is usually employed in research. The reason is that there is a lot of activities that were being operated on it at the same time and we want to focus only on resource sharing. First, in the methodology, we will introduce the unit of analysis we will use, second, we will expose the results we obtained and, finally, we will conclude with the limits of this work and the openings which it allows.

\section{Methodology}

\section{Analysis of the traces on BSCW}

The unit of research analysis concerning the CSCW on BSCW is often the total activity of the platform. This activity is analyzed through the various events which occurred: creation, modification, reading, removal of files, documents, threaded discussions... out of which statistics are processed. (Appelt $\&$ al, 01) post the percentages for the various types of events: creation of folders, documents, discussion, reading ... (Daradoumis \& al, 03) gathers the events in 4 categories: creation, modification, reading and removal. (Gonzalès \& al, 05) exploit the time of use, the number and the type of events: reading, creation of documents...It is rare for a treatment of units smaller than the total activity of the platform to be made. Nevertheless, a CSCW platform allows various types of activities to operate at the same time. Between an "on-line course with a teacher" use or a "resource sharing between peers" use such as the one considered here, neither the same events, nor the same organizations will be obtained. In the same way, it is rare for a distinction to be made between the constituted groups (e.g. the teacher with his trainees, the peers chosen between them...) in the publications. The categories suggested, when there is any, are very vast and are defined by the researchers themselves. For instance, (Appelt \& al, 01) distinguish between neophytes and confirmed users, (Gonzalès \& al, 05) distinguish between the training centers: Poland, Romania, Italy and Spain. So since the "type of activity" and "form of the groups" parameters are not taken into account, it is difficult to interpret the obtained results. Thus when (Daradoumis \& al, 03) check if all the users take part to CSCW, one can wonder whether the obtained results are related, or not, to the activities suggested and the constitutions of the groups. For our part, if we use a metaphor, we don't want to 
simply count the number of footprints left, we want to know where they go, what path they follow and to whom they belong.

\section{Unit of analysis: the higher level shared folder (hlsf)}

This is why what distinguishes our research from the preceding ones is the unit of analysis we have chosen. To define such a unit, we refer to one of the central ideas of the Activity Theory (Engeström, 87): the form of the activity depends of its goal. So, the unit we use, here, is the higher level shared folder (shortened to hlsf). The postulate is: the hlsf reflects the activity of the members of a group working together to solve a problem.

We defined the higher level shared folder in the following way (Simon \& al, 08) a hlsf is:

- a shared folder not belonging to any folder, in other words a shared folder which is at the root and which is thus contained in no other folder,

- or a shared folder belonging to a folder which is, itself, not a shared folder and which is at the root. A user can sometimes gather in the same folder (not shared) the folders which he/she shares with several different groups.

Defined in this way, it allows us to make distinctions between groups but also between the objectives (Dillenbourg \& al, 96) and thus to analyze the activity on the platform according to those two parameters.

In BSCW, information is organized hierarchically in folders and sub-folders and takes the form of various documents (texts, tables, URL...) which are created, read, modified, restructured... The hlsf is the widest response to the problem while one of its sub-folders, for its part, brings a response to a part of this problem. The problems are not the same, so the higher level shared folders will not be identical either.

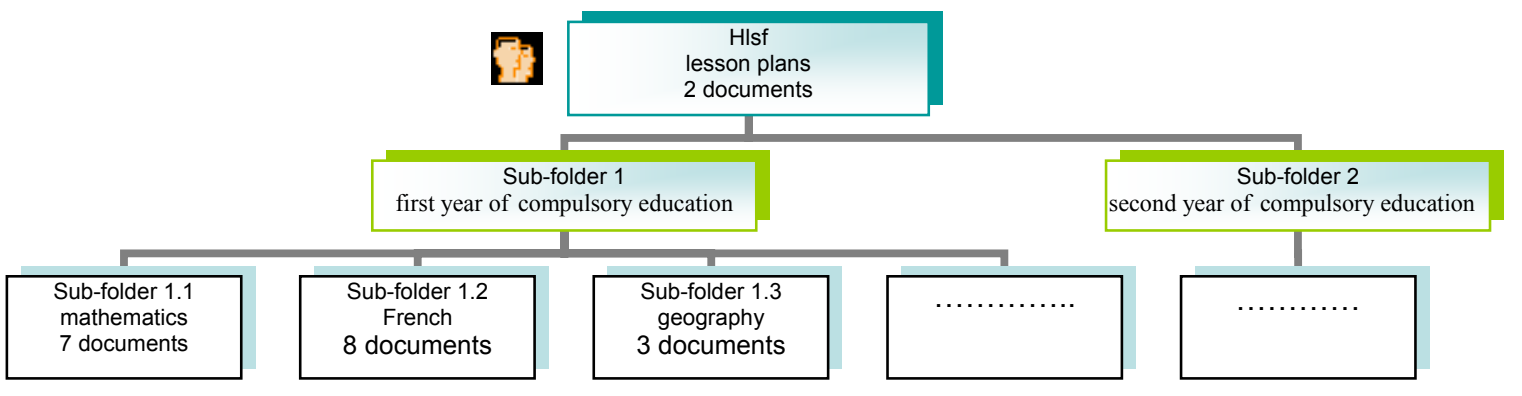

Figure 1. An example of $h l s f$. The heads symbolize the group of members associated with the hlsf. Each folder can itself contain sub-folders and documents

For a technical point of view, to analyze the data, we have translated the plain text file where BSCW stores all its data in tables which we worked with a relational DBMS (Gonzalès \& al, 05). In this plain text file, the user category of the PEs was distinguished from the others by the logins beginning by "PE2" (e.g.: PE2smith). That has made it possible to locate the hlsf only shared by them (without trainer). In this way, one notes that it is easy to automate the treatments.

\section{Results}

In what follows, we analyze the $h l s f s$ created by the different PEs of the IUFM for pooling and sharing their teaching resources during three years. It's important to note that, each year, this is a new cohort of PEs which comes to the IUFM to be trained and that, in the hlsfs we study here, there is no participation of trainers, the groups are constituted only of PEs. Moreover, each year, all the traces left by the previous cohort are deleted.

Table 1: Number of PE and number of hlsf they have created.

\begin{tabular}{|c|c|c|c|c|}
\hline & $2005-2006$ & $2006-2007$ & $2007-2008$ & over 3 years \\
\hline Number of hlsf & 289 & 189 & 89 & 567 \\
\hline Number of PE (trainees) & 343 & 277 & 217 & 837 \\
\hline Number of hlsfs for one PE & $\mathbf{0 , 8 4}$ & $\mathbf{0 , 6 8}$ & $\mathbf{0 , 4 1}$ & $\mathbf{0 , 6 8}$ \\
\hline
\end{tabular}

As we can note in Table 1, there are fewer and fewer trainees each year because the region needs fewer and fewer teachers. That's one of the reasons why there are also fewer and fewer hlsfs but it's not the only one. As we can see on the fourth line of this table the number of hlsfs for one PE is going down as well. We will explain that in the second section. In a first time, we will see if the results concerning 2005-2006 published in (Simon \& al, 2008) are still valid for the following years: participation, roles of the members... We will be interested in the members of the group associated with each hlsf and we will see up to what point there is an 


\section{CSCL PRACTICES IN EDUCATIONAL SETTINGS}

effective participation of each one and of which type this participation is. In a second time, we will observe the evolution of the $h l s f s$ structure and the evolution of the activity inside those $h l s f s$ during the three years.

\section{Confirmation of the results of 2005-2006}

Each hlsf is thus shared by a group of PE which upload, modify or consult resources which they use to prepare their lesson. The question is posed of the participation within the hlsf of each member of these groups. In (Simon \& al, 08) we have studied the hlsfs produced by the PE between September 2005 and August 2006. Most of the results remain true.

\section{Since 2006-2007 almost all the PE (98\%) belong to one h/sf at least}

Table 2 distributes the PE according to the number of $h l s f$ in which they take part. Over the three years, only 76 PEs, on the 837 PEs enrolled at the IUFM, didn't participate to a $h l s f$. Near $91 \%$ took part in one hlsf at least and since 2006-2007 almost all the PE (98\%) do it. More than 30\% of them took part in more than 10 hlsfs. As one will see more precisely below, one thus notes that the installation of a CSCW platform meets a real need.

Table 2: Participation of the PEs to one or more hlsf.

\begin{tabular}{|c|c|c|c|c|c|c|c|c|}
\hline & \multicolumn{2}{|c|}{$2005-2006$} & \multicolumn{2}{c|}{$2006-2007$} & \multicolumn{2}{c|}{$2007-2008$} & \multicolumn{2}{c|}{ sur les 3ans } \\
\cline { 2 - 9 } Number of $h l s f f$ & $\begin{array}{c}\text { Nb of PE } \\
\text { members }\end{array}$ & $\%$ & $\begin{array}{c}\text { Nb of PE } \\
\text { members }\end{array}$ & $\%$ & $\begin{array}{c}\text { Nb of PE } \\
\text { members }\end{array}$ & $\%$ & $\begin{array}{c}\text { Nb of PE } \\
\text { members }\end{array}$ & $\%$ \\
\hline 0 & 70 & $20,41 \%$ & 3 & $1,08 \%$ & 3 & $1,38 \%$ & 76 & $9,08 \%$ \\
\hline$>=1$ et $<10$ & 224 & $65,31 \%$ & 111 & $40,07 \%$ & 163 & $75,11 \%$ & 498 & $59,50 \%$ \\
\hline$>=10$ & 49 & $14,28 \%$ & 163 & $58,84 \%$ & 51 & $23,50 \%$ & 263 & $31,42 \%$ \\
\hline TOTAL & 343 & $100,00 \%$ & 277 & $100,00 \%$ & 217 & $100,00 \%$ & 837 & $100,00 \%$ \\
\hline
\end{tabular}

\section{But they use it differently}

To analyze the reality of this participation, we focused on the actions carried out in these hlsfs by the PEs, distinguishing between creation of a $h l s f$, creation of sub-folder in this $h l s f$, deposit of document in this $h l s f$, and simple reading. These actions are not the only ones but they are the basic actions impossible to circumvent.

Table 3: Numbers and percentages of PE according to various types of actions carried out.

\begin{tabular}{|c|c|c|c|c|c|c|c|c|}
\hline & \multicolumn{2}{|c|}{$2005-2006$} & \multicolumn{2}{|c|}{$2006-2007$} & \multicolumn{2}{|c|}{$2007-2008$} & \multicolumn{2}{c|}{ Over 3 years } \\
\hline Roles & $\begin{array}{c}\text { Nb of } \\
\text { PE }\end{array}$ & $\%$ & $\begin{array}{c}\text { Nb } \\
\text { of PE }\end{array}$ & $\begin{array}{c}\text { Nb } \\
\text { of } \\
\text { PE }\end{array}$ & $\begin{array}{c}\text { Nb } \\
\text { of } \\
\text { PE }\end{array}$ & $\%$ \\
\hline $\begin{array}{c}\text { Leader : creator of one } h l s f \text { at least } \\
\text { moderator : creator of one folder at least } \\
\text { in a } h l s f\end{array}$ & 107 & $31,20 \%$ & 114 & $41,61 \%$ & 58 & $26,73 \%$ & 279 & $33,33 \%$ \\
\hline $\begin{array}{c}\text { producer : creator of one document at } \\
\text { least in a } h l s f\end{array}$ & 150 & $43,73 \%$ & 158 & $57,04 \%$ & 111 & $51,15 \%$ & 419 & $50,06 \%$ \\
\hline $\begin{array}{c}\text { reader of one document at least } \\
\text { Inactive }\end{array}$ & 269 & $78,43 \%$ & 256 & $92,42 \%$ & 185 & $85,25 \%$ & 710 & $84,83 \%$ \\
\hline member of one $h l s f$ at least & 273 & $79,59 \%$ & 274 & $98,92 \%$ & 214 & $98,62 \%$ & 761 & $90,92 \%$ \\
\hline total number of PE & 343 & $100,00 \%$ & 277 & $100,00 \%$ & 217 & $100,00 \%$ & 837 & $100,00 \%$ \\
\hline
\end{tabular}

Table 3 has to be read as follows: when it's written that "x people have done....", it means "x different people". For instance, in 2005-2006, 150 different PEs are producers.

One notes the existence of "leaders" (33,33\% of the PEs who have created the hlsf), and the existence of "moderators" (38,47\% who have created folders). So, as we can see, leaders and moderators do not constitute a small minority of decision makers. Anyway, the terms leader and moderator should be used with some caution. Indeed, it is not because a user creates a hlsf or a subfolder that he launched the group. It can be imagined that the group would be established at the initiative of another person who has proposed to create a $h l s f$ and that the tasks have been distributed. We have studied the number of hlsf created on average by each leader, this one has decreased (from 2.70 in 2005-2006 to 1.53 in 2007-2008). At the opposite, the number of folders and sub-folders created on average by each moderator increases (from 1.55 to 5.32). This means that the organization of the hlsf is changing as we will see in the second part.

About $50 \%$ of the PEs were "producers" because they have created at least one document. The production is relatively constant for the two last years: a producer put on average about 6,5 documents on the 
platform in the hlsf. $84,83 \%$ of the PEs have consulted at least one document in a hlsf. Each year, one "reader" has consulted on average 20 documents. The number of "inactive" is the difference between the number of members and the number of readers. On average, over the three years, 6,09\% of the PEs were inactive. It can be assumed that these PEs were invited to participate in a hlsf by their colleagues but they were not really interested in it.

So, one notes through this table that the request of the PEs to pool and share resources was well founded because one PE out of three has created at least one hlsf or one subfolder, one out of two has produced at least one document and more than eight out of ten have read at least one document. In this way, when recalling the issue of the effectiveness of the members' participation, the latter can be said to be genuine. However, one notes an imbalance in the roles adopted by the PEs : if $84,83 \%$ of the members are "readers" and thus benefit from the resources on the platform, only 50,06\% are "producers" who took part in their installation. In the investigation (Simon, 06), PEs have been asked what the rules making resource sharing function could be. The one generally stated indicated that "one could receive only if one has given". Obviously, this rule was not complied with here and one can wonder how a system where near $35 \%$ of people take without giving would evolve if it were to be prolonged beyond one year.

\section{Analysis of the organization and the activity of the $h / s f$ over 3 years}

It's possible to refer to Figure 1 which depicts a $h l s f$ to read Table 4. One can see a lower number of $h l s f s$ due to the decreasing number of PEs but not only as evidenced by the ratio number of $h l s f s$ for one PE of Table 1 . Another reason is that the hlsfs were organized differently as we will see. One notes first, in Table 4, that the number of members by hlsf is rising. It's the same for the number of subfolders and, therefore, the depth of the $h l s f s$ is also increasing. The explanation for these two latter increases is, most likely, the steady increase of the number of documents put in the hlsfs. More members and more documents naturally bring more readings. To understand this phenomenon more deeply, our colleague (Gerard, 09) began to create the social network of each $h l s f$. We noticed, then, that many of them were with one producer only (remember that a producer is a member who deposits one document at least in the $h s l f$ ). So we analysed the $h l s f s$ according to the number of producers who work in it.

Table 4: Organization and activity of the $h l s f$.

\begin{tabular}{|c|c|c|c|c|}
\hline & $2005-2006$ & $2006-2007$ & $2007-2008$ & over 3 years \\
\hline Number $o f h l s f s$ & 289 & 189 & 89 & 567 \\
\hline Number of PEs & 343 & 277 & 217 & 837 \\
\hline Average number of members for one $h l s f$ & 8,3 & 15,45 & 16,67 & 12,00 \\
\hline Average number of documents for one $h l s f$ & 5,26 & 5,75 & 7,52 & 5,78 \\
\hline Average number of readings for one $h l s f$ & 25,51 & 28,53 & 47,06 & 30,62 \\
\hline Average number of subfolders for one $h l s f$ & 0,64 & 2,11 & 3,53 & 1,88 \\
\hline Percentage of $h l s f s$ with one level at least of subfolder & $16,28 \%$ & $31,75 \%$ & $37,08 \%$ & $24,70 \%$ \\
\hline
\end{tabular}

Table 5: Number of hlsf according to the number of producers who work in it .

\begin{tabular}{|c|c|c|c|c|c|c|c|c|}
\hline & \multicolumn{2}{|c|}{$2005-2006$} & \multicolumn{2}{c|}{$2006-2007$} & \multicolumn{2}{c|}{$2007-2008$} & \multicolumn{2}{c|}{ total } \\
\cline { 2 - 9 } & nb hslf & $\%$ & nb hslf & $\%$ & nb hslf & $\%$ & nb hslf & $\%$ \\
\hline 0 producer & 48 & $16,61 \%$ & 25 & $13,23 \%$ & 11 & $12,36 \%$ & 84 & $14,81 \%$ \\
\hline 1 producer & 198 & $68,51 \%$ & 108 & $57,14 \%$ & 21 & $23,60 \%$ & 327 & $57,67 \%$ \\
\hline 2 producers and more & 43 & $14,88 \%$ & 56 & $29,63 \%$ & 57 & $64,04 \%$ & 156 & $27,52 \%$ \\
\hline total & 289 & $100,00 \%$ & 189 & $100,00 \%$ & 89 & $100,00 \%$ & 567 & $100,00 \%$ \\
\hline
\end{tabular}

As one can see in the Table 5, the evolution is the same than the one pointed out previously: the number of $h l s f s$ with two or more producers is growing up each year, from $15 \%$ to $64 \%$.

Thus we see that there are fewer hlsfs but they are more complete, better structured and more active. It seems that, implicitly, PEs follow the rule laid down by their colleagues (Simon, 06): there should be a sufficient number of members and documents for pooling and sharing properly.

\section{Conclusion}

Firstly, considering the results, the analysis seems to show that resource sharing works. Nearly $90 \%$ of the teacher trainees of the IUFM freely decided to be a member of a $h l s f$ and among them almost all used the resources. Thus, one can make the assumption that individuals use a tool when they see the profit which they can draw from it. But we have to be careful because only $50 \%$ of the members have put some documents on the 


\section{CSCL PRACTICES IN EDUCATIONAL SETTINGS}

platform. Moreover this assessment has to be moderated in another way. Behind the idea of resource sharing, there is also the idea of improvement of the resources. In the investigation (Simon, 06), the trainees claimed that they wanted a return on the resources that they had deposited after they had been used. This return under BSCW can be done in various forms: adding a note to the document, modifying the latter... It appears, after analysis of this type of events, that it occurred rarely. We are thus more in cooperation than in collaboration (Dillenbourg \& al, 96). One can note also that the organization of the hlsf is evolving: the hlsf are fewer, but they are more complete, better structured, and more active. What we are going to do now is to categorize the hlsfs in, at least, two categories (fewer or more than two producers) and study them separately because we believe that they don't pursue exactly the same objective.

Secondly, considering the method used in this research, it appears that the unit of analysis suggested, the higher level shared folder, $h l s f$, enables to produce some results. The activities on a CSCW platform are not different from those in real life and obey the same logic: a group of individuals link their efforts to solve a problem. It is necessary to distinguish the activities according to the objectives and according to the groups which perform them because the form that the activity takes (number of participants, type of organization,...) depends on the goal, the problem to be solved (Engeström, 87). Within the framework of the CSCW, when taking as unit of analysis the total activity of the platform, this particular parameter which is the problem to be solved is lost. Indeed, it is rare for a platform to be dedicated only to one type of activity. Consequently, analyzing the total activity of the platform amounts to pooling various things in the same activity. This is why we think that the hlsf is a relevant unit of analysis because it makes it possible to distinguish between the types of activity and leads to more precise results. For instance, in (Simon \& al, 08), we have studied all the hlsfs. They were separated in two classes: those where there is a trainer and those where the trainer is missing (like here). It is noted there that the produced $h l s f s$ do not adopt the same form in both cases.

The analysis of the hlsf is a method which comes under the field of trace analysis, and the limits of the latter start to be known. It is often reproached with remaining superficial and in general it is proposed to be supplemented by others in order to go more in-depth (e.g. mixed method (Martinez \& al, 06)). This is why the tendencies raised here and the suggested interpretations would require confirmation by other processes: directed investigations, interviews... For the moment, we work on the social networks analysis of the groups associated with the hslfs (Gerard, 09). We have also handed a questionnaire to the PEs of the previous years to understand how the hslf have been negotiated among them (Stahl, 03).

\section{References}

Appelt W. (2001). What Groupware Functionality Do Users Really Use? Analysis of the Usage of the BSCW System. Ninth Euromicro Workshop on Parallel and Distributed Processing (PDP'01), Mantova, Italy, p. 337-341.

Bentley R., Appelt W., Busbach U., Hinrichs E., Kerr D., Sikkel K., Trevor J., Woetzel G. (1997). Basic Support for Cooperative Work on the World Wide Web. International Journal of Human Computer Studies: Special issue on Novel Applications of the WWW, Spring 1997, Academic Press, Cambridge, vol. 46, no6, p. 827-846.

Daradoumis T., Xhafa F., Marquès J.M. (2003). Is an 'Effective' Online Group Really Effective? Proceedings of the Spanish Workshop on Trabajo en Grupo y Aprendizaje Colaborativo: experiencias y perspectiva. November 11, Donostia, p. 75-82.

Dillenbourg, P., Baker, M., Blaye, A. \& O'Malley, C.(1996) The evolution of research on collaborative learning. In E. Spada \& P. Reiman (Eds) Learning in Humans and Machine: Towards an interdisciplinary learning science. (Pp. 189-211). Oxford: Elsevier.

Engeström Y. (1987). Learning by expanding: An Activity-Theoretical Approach to Developmental Research. Orienta-Konsultit Oy.

Gerard J-P, (2009). Analyse des réseaux sociaux associés aux dpphn créés par les PE2 seuls à l'IUFM de La Réunion, submitted at EPAL, 2009, Grenoble

González V.R., García de la Santa A., Gorghiu G., Gorghiu L.M. (2005). BSCW as a support system for distance teacher training. Recent Research Developments in Learning Technologies, Proceedings of the Third International Conference on Multimedia \& ICT's in Education, vol. 2, p. 696-701.

Martınez A., Dimitriadis Y., Gomez E., Jorrın I., Rubia B., Marcos J.A. (2006). Studying participation networks in collaboration using mixed methods. International Journal of Computer-Supported Collaborative Learning, Springer New York. Vol. 1, n`3, September, p. 383-408.

Simon J. (2006). Mutualiser entre pairs, Expressions, Saint Denis, n²7, p. 127-133

Simon J, Gerard JP, Thevenin C., (2008), Dossiers partagés par les stagiaires avec ou sans formateur à l'IUFM de La Réunion: Analyses des traces. In STICEF Volume 15, 2008, Numéro spécial EPAL, Grenoble, 2007

Stahl G, Knowledge Negotiation in Asynchronous Learning Networks. Proceedings of the 36th Hawaii International Conference on System Sciences (HICSS'03), Hawaii. 